\title{
Chrysoperla Steinmann, 1964 (Neuroptera, Chrysopidae): descrição de uma nova espécie do Brasil
}

Sérgio de Freitas ${ }^{1}$

\begin{abstract}
Chrysoperla Steinmann, 1964 (Neuroptera, Chrysopidae): description of a new species from Brazil. Chrysoperla genanigra sp. nov., is described from Pau Branco, Rio Grande do Norte, Brazil. A key to the Brazilian species of Chrysoperla is added.
\end{abstract}

Keywords. Chrysoperla; Chrysopidae; green lacewing; taxomomy.

\section{INTRODUÇÃO}

Steinmann, (1964) descreveu Chrysoperla como um subgênero de Chrysopa Leach, designando como espécie-tipo C. carnea Stephens. Esta determinação não foi considerada consistente porque se baseava em características da morfologia da cabeça e manchas cefálicas. TJEDER (1966) propôs o reagrupamento das espécies de Chrysopidae através do uso de características da genitália masculina. O gênero Chrysopa foi dividido em 8 subgêneros. Em um dos subgêneros, Chrysopa (Chrysoperla), foram agrupadas aquelas espécies cuja genitália masculina possuía tignum (estrutura supragonarcus, arqueada e com pequena projeção caudal mediana), no entanto a gonapsis (estrutura infragonarcus longa e estreita) estava ausente. SÉMÉRIA (1977) propôs a elevação de C. (Chrysoperla) a status de gênero. Brooks \& BARnARD (1990), em sua revisão de gêneros de Chrysopidae, reconheceram a individualidade de Chrysoperla.

As espécies de Chrysoperla podem ser reconhecidas pelas seguintes características: corpo de coloração verde com faixa dorsal longitudinal amarela; antenas com escapo e pedicelo sem manchas ou listras e flagelo de coloração âmbar na base e fusco no ápice; gena freqüentemente pigmentada de vermelho; fronte palha podendo ter as margens laterais em vermelho difuso; clípeo palha, às vezes com as margens laterais vermelhas; mandíbulas assimétricas; pronoto sem faixas laterais mas com manchas laterais dispersas cinza ou marrom; meso- e metanoto sem manchas; asas longas e estreitas, sem manchas, pterostigma hialino, célula intramediana curta com laterais curvas; veias verdes, as gradiformes podem ser pretas; abdome sem manchas; ápice do 8+9 esternito do macho com pequena projeção lobular, presença de tignum, acumen estreito, longo ou curto; gonossacus com gonosetae; ausência de gonapsis; arcessus estreito. Chrysoperla é o único gênero que possui microcerdas denominadas espinelas associadas ao gonossacus (BRooks \& BARNARD 1990).

No Brasil podem ser encontradas quatro espécies (Figs. 711): Chrysoperla externa (Hagen, 1861), C. defreitasi Brooks, 1994, C. raimundoi Freitas \& Penny, 2001 (Freitas \& Penny 2001) e C. genanigra sp. nov. Esses insetos possuem espinelas formadas por cinco ou mais espinhos por tubérculo; gonarcus estreito; acumen (processo mediano do tignum) estreito e dilatado no ápice (BROoKs 1994).

\section{Chrysoperla genanigra sp. nov.}

(Figs. 1-8)

Holótipo macho. BRASIL. Rio Grande do Norte, Mossoró, Pau Branco, 10.II.2002 (L. K. F. Silva), (MZSP - Museu de Zoologia, Universidade de São Paulo). Parátipos: 1 macho e 3 fêmeas, mesmos dados do holótipo (Departamento de Fitossanidade, UNESP - Jaboticabal, São Paulo).

Diagnose. A principal característica desta espécie, é a coloração preta da gena, margem lateral do clípeo e lateral da maxila.

Cabeça. Vértice amarelo, achatado, sem estriações transversais; fronte sem manchas (Fig. 7); margem lateral do clípeo de coloração preta (Fig. 7); genas com manchas pretas não atingindo as margens (Fig. 8); palpos maxilares escuros dorsalmente (Fig. 8); escapo, pedicelo e flagelo amarelo-claros. 

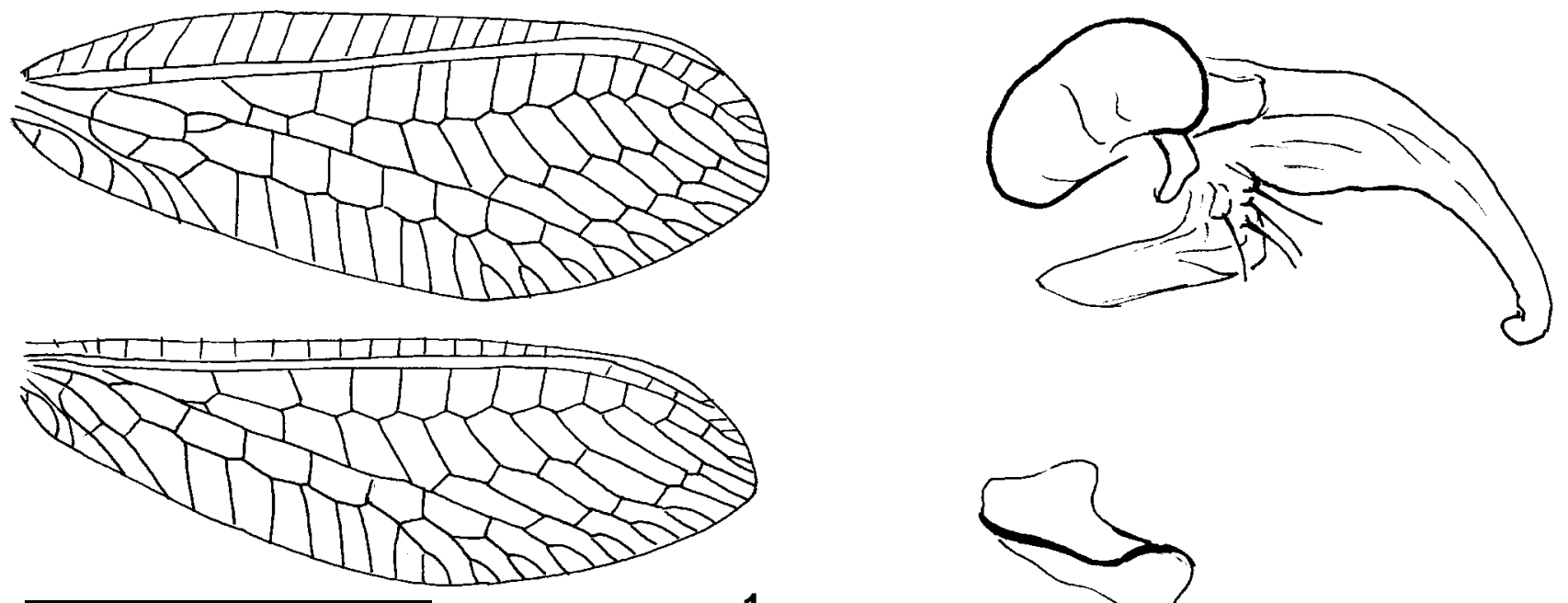

1
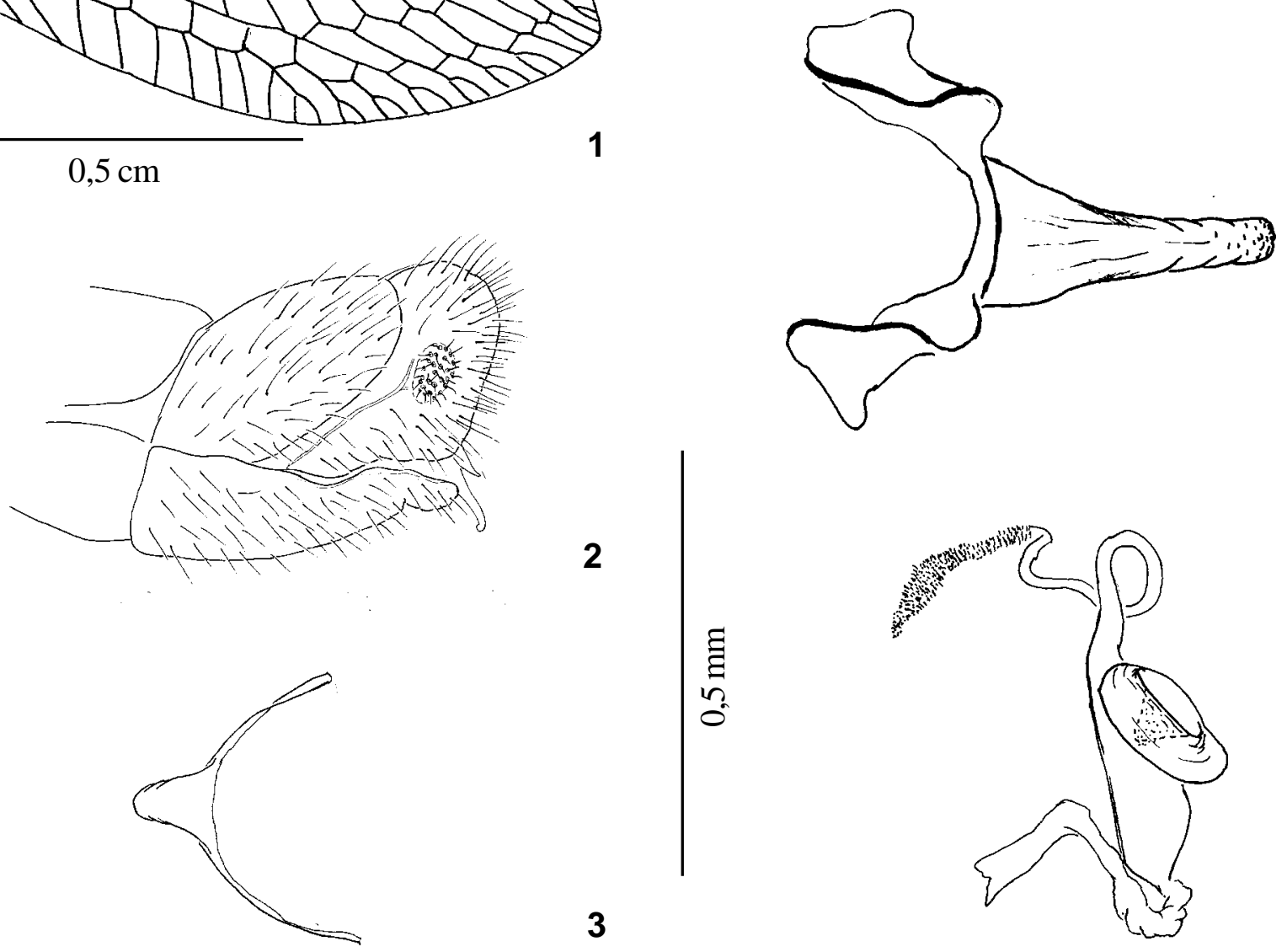

2

3

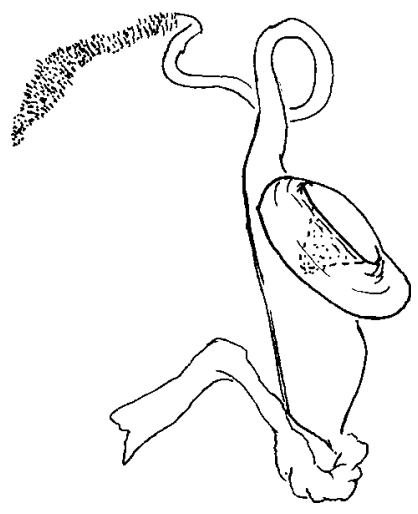

6

Figs. 1-6. Chrysoperla genanigra sp. nov.: 1, asas anterior e posterior; 2, ápice do abdome, vista lateral; 3, tignum, vista dorsal; 4, complexo do gonarcus, vista lateral; 5, idem, vista dorsal; 6, espermateca, vista lateral.

Tórax. Verde, com linha mediana dorsal amarela; pronoto com mancha látero-anterior cinza; base das cerdas pretas; mesoe metanoto sem manchas. Asas anteriores (Fig. 1): venação verde; comprimento $(1,19 \mathrm{~cm})$ : largura $(0,29 \mathrm{~cm})=4,1$. Asas posteriores: venação verde; comprimento $(1,17 \mathrm{~cm})$ : largura $(0,32 \mathrm{~cm})=3,6$.

Abdome. Verde-amarelado com faixa amarela na linha mediana dorsal, sem manchas. Macho: ápice do 8+9 esternito com processo globoso (Fig. 2), tignum alongado, muito estreito com acumen triangular (Fig. 3); gonarcus estreito e pouco arqueado, braço lateral robusto (Figs. 4,5); arcessus muito estreito, curvado na base e na extremidade; gonossacus com poucas cerdas longas (Figs. 4,5). Fêmea: espermateca curta (Fig. 6).

Comentários. C. genanigra sp. nov. é muito semelhante às outras espécies de Chrysoperla que ocorrem no Brasil, distinguindo-se por ser a única com manchas negras na gena (Figs. 7-11). Os exemplares estudados foram coletados em plantação de melão. 

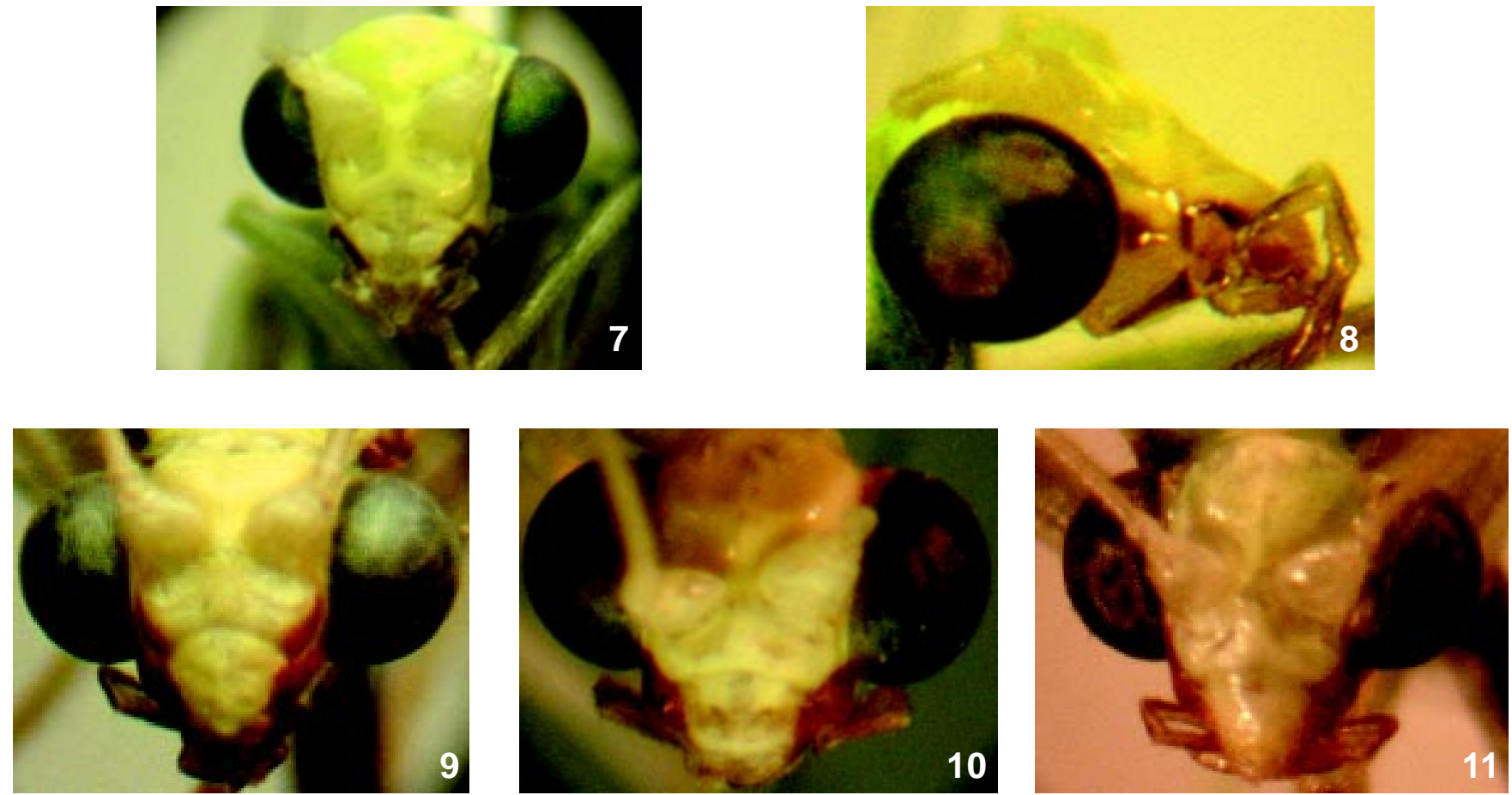

Figs. 7-11. Espécies brasileiras de Chrysoperla: 7-8, C. genanigra sp. nov.; 9, C. defreitasi Brooks, 1994; 10, C. externa (Hagen, 1861); 11, C. raimundoi Freitas \& Penny, 2001.

Chave para espécies de Chrysoperla do Brasil

1. Genas com coloração vermelha Genas com coloração preta C. genanigra sp. nov.

2(1). Asa anterior com veias verdes Asa anterior com gradiformes pretas C. defreitasi Brooks, 1994

3(2). Arcessus fracamente curvado apicalmente C. externa (Hagen, 1861) Arcessus fortemente curvado apicalmente . C. raimundoi Freitas \& Penny, 2001

\section{REFERÊNCIAS}

Brooks, S. J. 1994. A taxonomic review of the common green lacewing genus Chrysoperla (Neuroptera: Chrysopidae). Bulletin of the British Museum of Natural History, Entomology Series 63(2): 137-210.

Brooks, S. J. \& P. C. Barnard. 1990. The green lacewings of the world: a generic review (Neuroptera:Chrysopidae). Bulletin of the British Museum of Natural History, Entomology Series 59: 117-286.

Freitas, S. \& N. D. Penny. 2001. The green lacewings (Neuroptera, Chrysopidae) of Brazilian agro-ecosystems. Proceedings of the California Academy of Sciences 52: 245-395.

SÉMÉRIA, Y. 1977. Discussion de la validité taxonomique du sous-genre Chrysoperla Steinmann. Nouvelle Revue d'Entomologie 7: 235238.

Steinmann, H. 1964. The Chrysopa species (Neuroptera) of Hungary. Annales Historico-Naturales Musei Nationales Hungarici 56: 257-266.

TJeder, B. 1966. Neuroptera - Planipennia 5. Family Chrysopidae. South African Animal Life 12: 228-534. 